\title{
Low-damage milling of an amino acid thin film with cluster ion beam
}

\section{$\operatorname{AUTHOR}(\mathrm{S})$ :}

Hada, Masaki; Ibuki, Sachi; Hontani, Yusaku; Yamamoto, Yasuyuki; Ichiki, Kazuya; Ninomiya, Satoshi; Seki, Toshio; Aoki, Takaaki; Matsuo, Jiro

\section{CITATION:}

Hada, Masaki ...[et al]. Low-damage milling of an amino acid thin film with cluster ion beam. JOURNAL OF APPLIED PHYSICS 2011, 110(9): 094701.

\section{ISSUE DATE:}

2011-11

URL:

http://hdl.handle.net/2433/160646

\section{RIGHT:}

Copyright 2011 American Institute of Physics. This article may be downloaded for personal use only. Any other use requires prior permission of the author and the American Institute of Physics. The following article appeared in JOURNAL OF APPLIED PHYSICS 110, 094701 (2011) and may be found at http://link.aip.org/link/?jap/110/094701 


\section{AIP $\mid$ Applied Physics}

\section{Low-damage milling of an amino acid thin film with cluster ion beam}

Masaki Hada, Sachi Ibuki, Yusaku Hontani, Yasuyuki Yamamoto, Kazuya Ichiki et al.

Citation: J. Appl. Phys. 110, 094701 (2011); doi: 10.1063/1.3658220

View online: http://dx.doi.org/10.1063/1.3658220

View Table of Contents: http://jap.aip.org/resource/1/JAPIAU/v110/i9

Published by the American Institute of Physics.

\section{Related Articles}

Comparative band alignment of plasma-enhanced atomic layer deposited high-k dielectrics on gallium nitride J. Appl. Phys. 112, 053710 (2012)

In situ transmission electron microscopy study of dielectric breakdown of surface oxides during electric fieldassisted sintering of nickel nanoparticles

Appl. Phys. Lett. 101, 093107 (2012)

Excimer laser ablation of thick SiOx-films: Etch rate measurements and simulation of the ablation threshold Appl. Phys. Lett. 101, 091901 (2012)

Localized removal of layers of metal, polymer, or biomaterial by ultrasound cavitation bubbles Biomicrofluidics 6, 034114 (2012)

Method of electrochemical etching of tungsten tips with controllable profiles

Rev. Sci. Instrum. 83, 083704 (2012)

\section{Additional information on J. Appl. Phys.}

Journal Homepage: http://jap.aip.org/

Journal Information: http://jap.aip.org/about/about_the_journal

Top downloads: http://jap.aip.org/features/most_downloaded

Information for Authors: http://jap.aip.org/authors

\section{ADVERTISEMENT}

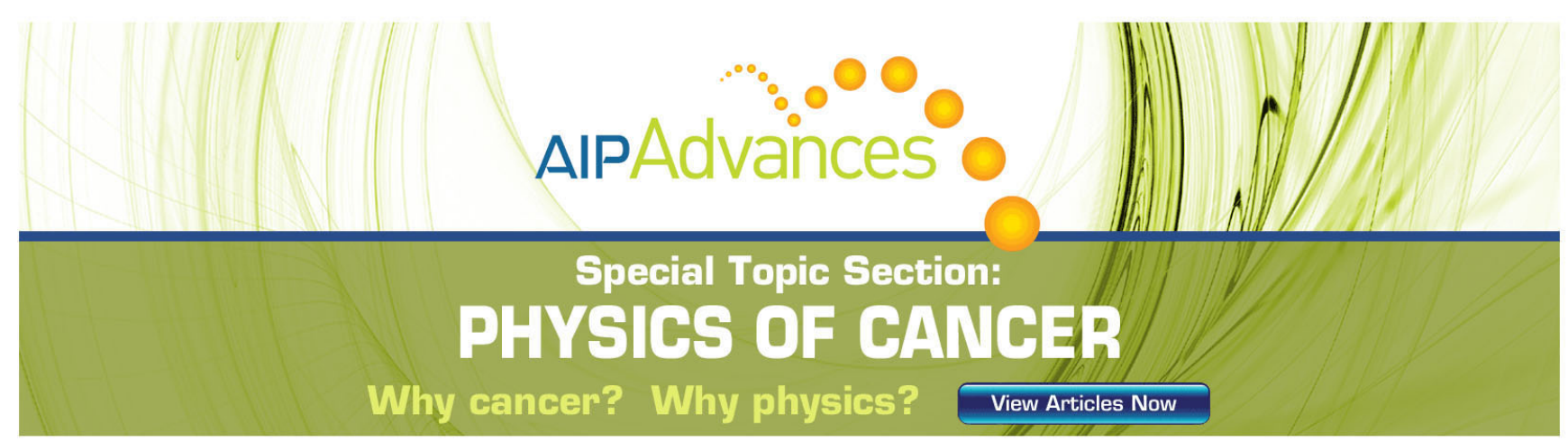




\title{
Low-damage milling of an amino acid thin film with cluster ion beam
}

\author{
Masaki Hada, ${ }^{1, a), b)}$ Sachi Ibuki, ${ }^{1}$ Yusaku Hontani, ${ }^{2}$ Yasuyuki Yamamoto, ${ }^{2}$ Kazuya Ichiki, ${ }^{2}$ \\ Satoshi Ninomiya, ${ }^{1}$ Toshio Seki, ${ }^{2}$ Takaaki Aoki, ${ }^{3}$ and Jiro Matsuo ${ }^{1, c)}$ \\ ${ }^{1}$ Quantum Science and Engineering Center, Kyoto University, Uji 611-0011, Japan \\ ${ }^{2}$ Department of Nuclear Engineering, Kyoto University, Kyoto 606-8501, Japan \\ ${ }^{3}$ Department of Electronic Science and Engineering, Kyoto University, Kyoto 615-8530, Japan
}

(Received 25 August 2011; accepted 29 September 2011; published online 2 November 2011)

\begin{abstract}
In this work, we characterized the surface damage layer and sputtering yield of polycrystalline L-leucine films before and after irradiation with Ar cluster or monomer ion beams with $\mathrm{x}$ ray photoelectron spectroscopy and ellipsometry. Irradiation with Ar monomer ion beams induced heavy damage on the surface of L-leucine films, such as bond breaking and carbonization. In contrast, no significant surface damage was observed in the films irradiated with Ar cluster ion beams. The sputtering yield of L-leucine decreased dramatically with increasing fluence of monomer Ar ions and approached the value of the sputtering yield of graphite; but under irradiation with Ar cluster ion beams, the sputtering yield remained constant with fluence. The differences in sputtering yield behavior were explained in relation with the surface damage layer on organic materials. Thus, cluster ion beams could potentially be used to mill down biological materials without significant damage on the surface and could contribute to various applications in the analysis and processing of life matter. (C) 2011 American Institute of Physics. [doi:10.1063/1.3658220]
\end{abstract}

\section{INTRODUCTION}

Because of its potential in the fields of nanoscaled fabrication ${ }^{1-3}$ and mass analysis of organic and biological materials, ${ }^{4,5}$ ion beam technology has attracted much interest in the research community. Chemical etching and methods of direct slicing, i.e., microtome, have been applied in the fabrication of organic devices and analysis of the surface or the bulk of organic and life matter. The need for ion beam etching (milling) of organic materials without damage to the structure has been identified for fabrication and analysis. Irradiation with a conventional ion beam induces heavy damage on the surface of organic materials, including effects such as chemical bond breaking, recombination, and carbonization. ${ }^{6,7}$ The carbonization occurs in irradiation with ion beams because of the "selective sputtering" effect, which refers to the fact that oxygen, hydrogen, and nitrogen are sputtered from the sample surface at a higher yield than carbon. The carbonized layer thickness accumulates to eventually reach the projection range of the ion beam. Carbonization often reduces the sputtering (milling) rate of the organic materials, resulting in an inhomogeneous surface.

Gas cluster ion beams consist of several hundred to several thousand atoms or molecules, and, as reported, its irradiation effects on organic or polymeric materials are completely different from those of a monomer ion beam, with high sputtering yield and low damage. ${ }^{5,8-11}$

L-leucine $\left(\mathrm{C}_{6} \mathrm{H}_{13} \mathrm{NO}_{2}, 131 \mathrm{u}\right)$ is one of the essential amino acids and is a common substance in living cells. It consists of fundamental elements of biological materials, namely

\footnotetext{
${ }^{\text {a)} E l e c t r o n i c ~ m a i l: ~ m a s a k i . h a d a @ m p s d . c f e l . d e . ~}$

b) Present address: Max Planck Research Department for Structural Dynamics at the University of Hamburg, Center for Free Electron Laser Science, c/o DESY, Notkestrasse 85, Hamburg 22607, Germany.

${ }^{c}$ Electronic mail: matsuo@nucleng.kyoto-u.ac.jp.
}

carbon, hydrogen, nitrogen, and oxygen, and therefore was considered to be very appropriate to investigate the ion beam irradiation effect on organic materials. The damage on the L-leucine films irradiated with high fluence $\left(\sim 10^{15}\right.$ ions $\left./ \mathrm{cm}^{2}\right)$ of $\mathrm{Ar}$ cluster or monomer ion beams has been investigated with scanning electron microscope, secondary ion mass spectrometry, and ellipsometry. The surface of the L-leucine completely changed to carbon structure with irradiation of an $\mathrm{Ar}$ monomer ion beam. In contrast, changes were not observed on the surface of the L-leucine film irradiated with Ar cluster ion beams. In this study, we used x-ray photoelectron spectroscopy (XPS) and ellipsometry to evaluate the surface damage layer and sputtering yield of polycrystalline L-leucine film after irradiation with a large Ar gas cluster or conventional monomer Ar ion beam. We focused on the chemical bond breaking of L-leucine with irradiation of relatively low fluence $\left(\sim 10^{13}\right.$ ions $\left./ \mathrm{cm}^{2}\right)$ of $\mathrm{Ar}$ cluster or monomer ion beams. XPS enables sensitive measurements of the chemical bonds on the sample surface $(5-10 \mathrm{~nm})$, and ellipsometry can determine film thickness of very soft organic materials. These procedures could be adopted for characterization of ion-beam damaged surface layers in organic materials.

\section{EXPERIMENTAL PROCEDURE}

The L-leucine films were deposited on crystalline silicon (c-Si) substrates. The substrate wafers were cleaned of any residual organic materials in a cleaning cycle using water, acetone, trichloroethylene, acetone, and water again, $10 \mathrm{~min}$ for each fluid, in an ultrasonic bath. After cleaning, the wafers were dried with nitrogen gas. L-leucine was deposited in a vacuum chamber (evacuated to $4 \times 10^{-5} \mathrm{~Pa}$ with a cryogenic pump) by thermal evaporation using a tantalum boat. The deposition rate was $0.4-0.6 \mathrm{~nm} / \mathrm{s}$, the film was $120 \mathrm{~nm}$ thick, and its density was $\sim 0.80 \mathrm{~g} / \mathrm{cm}^{3}(\sim 70 \%)$, obtained 
using a 20-nm-thick L-leucine film with $\mathrm{x}$ ray reflective (XRR) measurements (see Fig. 1 for a typical spectrum). ${ }^{12,13}$ The L-leucine films were characterized as polycrystalline using $\mathrm{x}$ ray diffraction (XRD) with $\mathrm{Cu} \mathrm{K} \alpha \mathrm{x}$ ray radiation and a computer-controlled reflectometer (Rigaku, ATX-G, $18 \mathrm{~kW})$. The mean grain size was calculated as $\sim 40 \mathrm{~nm}$ based on the full-width-half-maximum (FWHM) of the XRD line of the L-leucine (100) plane ${ }^{14,15}$ and the Scherrer equation (Fig. 2). ${ }^{16,17}$ Surface roughness was measured with atomic force microscopy (AFM) (Shimadzu, SPM9500J2) and the AFM tomography image was taken in the tapping mode. The average surface roughness (Ra) was $\sim 4 \mathrm{~nm}$ on a scanning area of $10 \mu \mathrm{m} \times 10 \mu \mathrm{m}$ (Fig. 3). The deposited film with surface roughness of $\sim 4 \mathrm{~nm}$ consisted of $70 \%$ polycrystalline L-leucine with a mean grain size of $\sim 40 \mathrm{~nm}$ and $30 \%$ vacancies.

To generate the Ar gas cluster ion beam, we used the adiabatic expansion of a high-pressure argon through a nozzle. The neutral clusters were ionized by electron bombardment at a voltage of $300 \mathrm{~V}$ and a current of $50 \mathrm{~mA}$ and were electrostatically accelerated in this work to 10 or $20 \mathrm{keV}$. Monomer ions were removed from ion beam with strong magnetic fields. The source gas pressure was $5.3 \times 10^{5} \mathrm{~Pa}$, and the mean size of the Ar cluster ion beam was 5000, as measured using the time-of fight method. The irradiation fluence of the Ar cluster ion beams was $2.0 \times 10^{13}-2.5 \times 10^{14}$ ions $/ \mathrm{cm}^{2}$. To compare between irradiation effects of cluster and monomer ion beams, the L-leucine films were also irradiated with $\mathrm{Ar}$ monomer ion beams accelerated to $10 \mathrm{keV}$, and the properties were characterized with the same procedure. The ion fluence of the $\mathrm{Ar}$ monomer ion beams was also $2.0 \times 10^{13}-5.0 \times 10^{14}$ ions $/ \mathrm{cm}^{2}$.

The surface of the L-leucine films was characterized with XPS with $\mathrm{Al} \mathrm{K} \alpha \mathrm{x}$ ray radiation (ULVAC-PHI Quantum-2000). Irradiation with an Ar cluster ion beam was performed at the acceleration voltage of $10 \mathrm{keV}$ and $20 \mathrm{keV}$ and with the Ar monomer ion beam at the acceleration voltage of $10 \mathrm{keV}$. The ion fluence was $2.0 \times 10^{13} \mathrm{ions} / \mathrm{cm}^{2}$. The $\mathrm{x}$ ray beam spot was $20 \mu \mathrm{m}$ in diameter, and the take-off angle of the photoelectron was $45^{\circ}$. XPS spectra were taken in the narrow condition, i.e., near the range of C 1s (276-296eV),

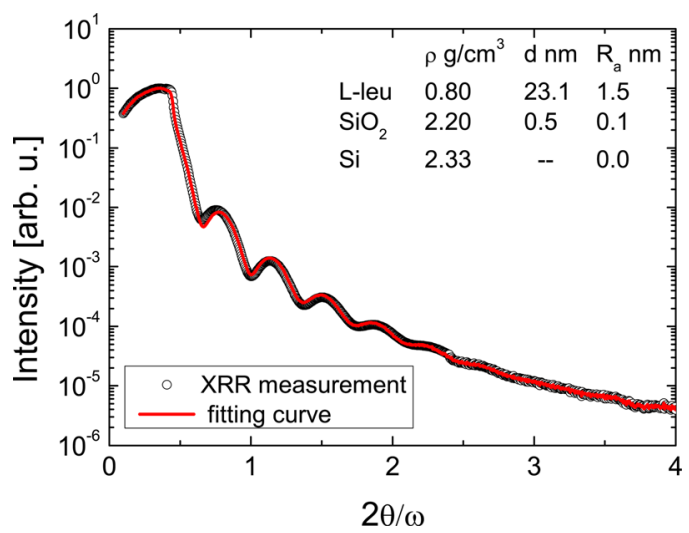

FIG. 1. (Color online) XRR spectrum obtained from the L-leucine. The fitting curve was calculated in the multilayer model of the XRR software with the shown fitting parameters (density $(\rho)$, thickness (d), and surface roughness $\left(\mathrm{R}_{\mathrm{a}}\right)$ ).

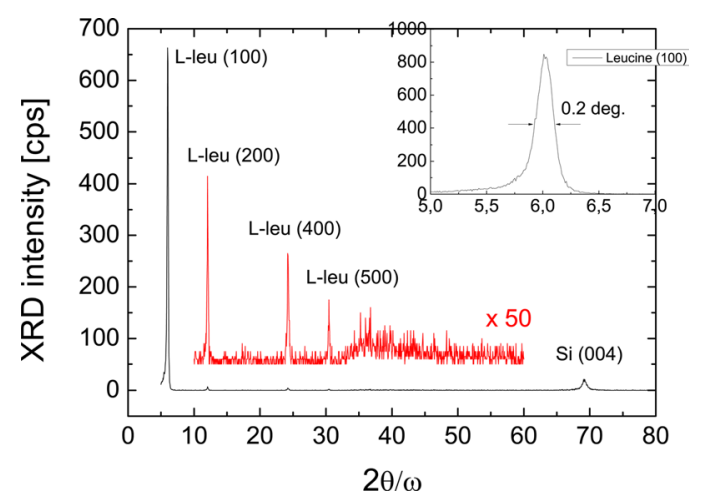

FIG. 2. (Color online) XRD spectrum of the L-leucine film showing diffraction lines from the (100) plane and multi-order lines of the same plane. The FWHM of (100) line was $0.2^{\circ}$ (inset).

$\mathrm{N}$ 1s $(392-412 \mathrm{eV})$, and $\mathrm{O}$ 1s $(525-545 \mathrm{eV})$. The probing depth of XPS was $5-10 \mathrm{~nm}$, as determined by the escaping depth of an emitted photoelectron from the sample. The thickness of the L-leucine film was also measured using conventional single-wavelength $(635 \mathrm{~nm})$ ellipsometry before and after irradiation with an Ar cluster or monomer ion beams. The incident angle of the laser was $75^{\circ}$. The refractive index of L-leucine film of $70 \%$ density was calculated as 1.37 with an effective medium approximation model. ${ }^{13,18,19}$

\section{RESULTS AND DISCUSSION}

Changes in the chemical bonds of L-leucine at the probing depth of $5-10 \mathrm{~nm}$ were observed with XPS. The sputtered film depth $(10-20 \mathrm{~nm})$ was larger than the surface roughness value $(\sim 4 \mathrm{~nm})$, but shorter than the mean grain size of the L-leucine crystal $(\sim 40 \mathrm{~nm})$; therefore, an accurate analysis could be operated with this probing depth. The XPS spectra near the range of $\mathrm{C} 1 \mathrm{~s}, \mathrm{~N} 1 \mathrm{~s}$, and $\mathrm{O} 1 \mathrm{~s}$, respectively, are shown in Figs. 4(a)-4(c). The core level electrons ejected from each atom, which is influenced by bonding environments, and small chemical shift indicates the bonding environments. In the spectrum near the range of $\mathrm{C} 1 \mathrm{~s}$ from the as-received (unirradiated) film (Fig. 4(a)), the peak at $\sim 285 \mathrm{eV}$ corresponds to $\mathrm{C}-\mathrm{C}, \mathrm{C}-\mathrm{H}(284.8 \mathrm{eV})$, and $\mathrm{C}-\mathrm{N}$

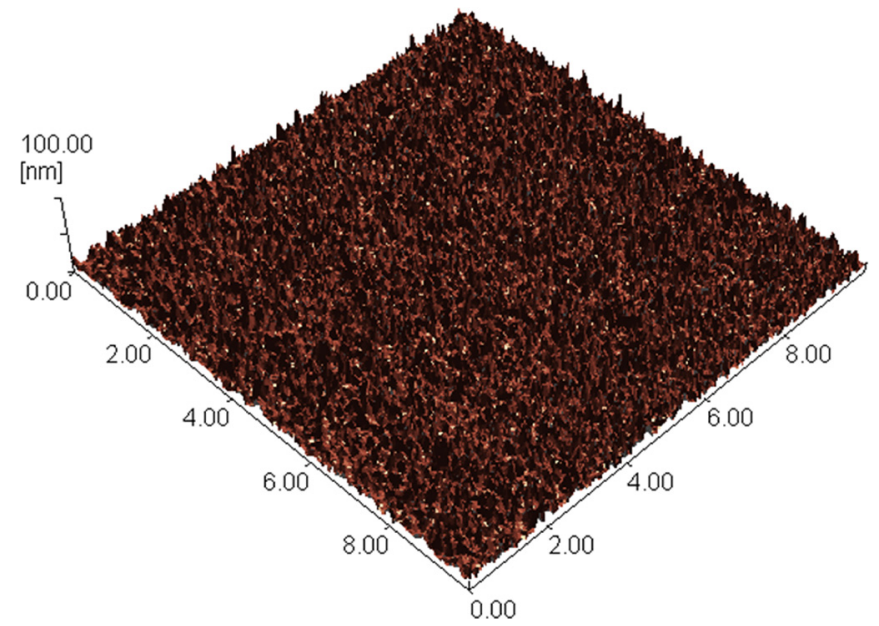

FIG. 3. (Color online) AFM tomography image on the surface of the L-leucine film. 

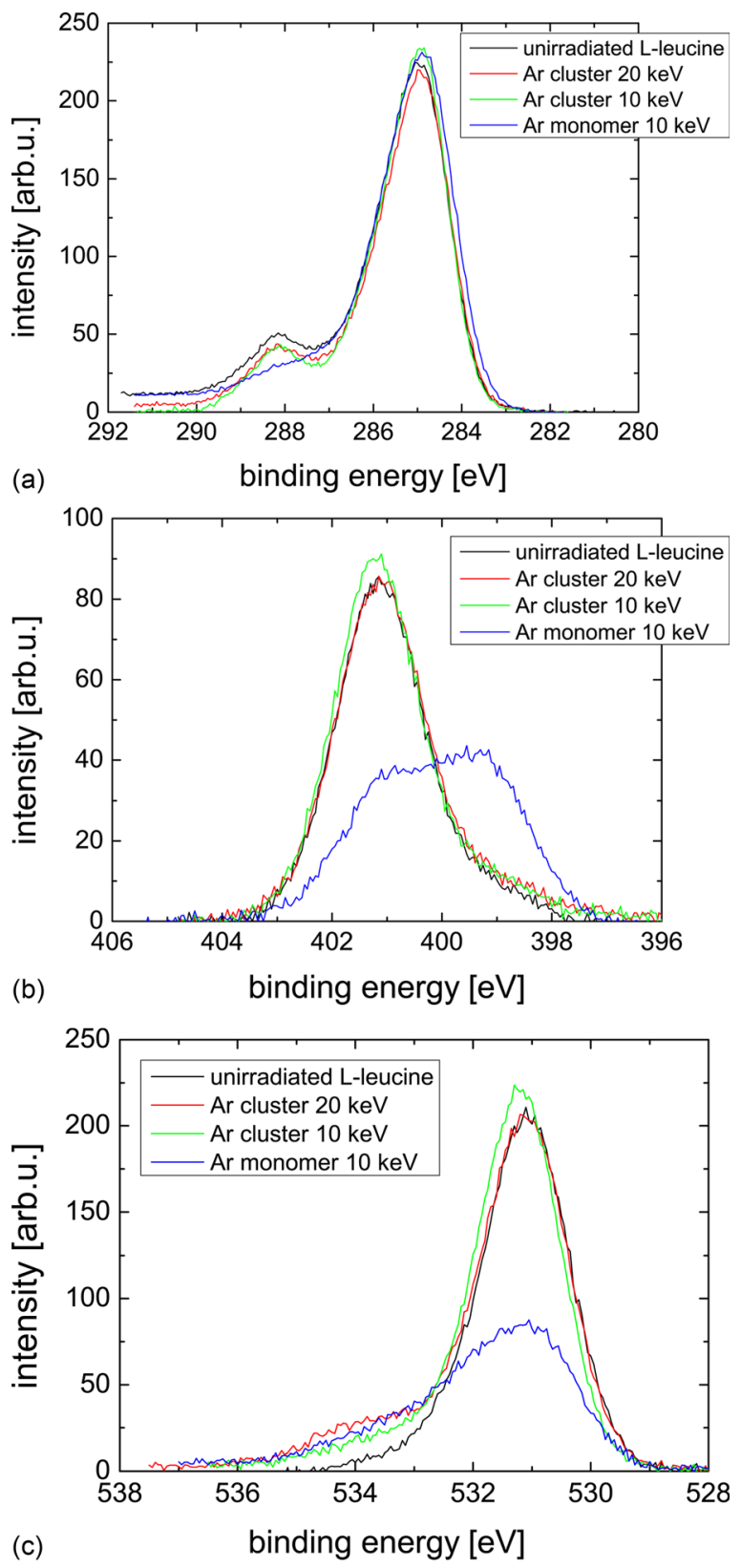

FIG. 4. (Color online) XPS spectra from the L-leucine films before and after irradiation with Ar cluster or monomer ion beams near the range of $\mathrm{C} 1 \mathrm{~s}$ (a), $\mathrm{N}$ 1s (b), and O 1s (c). (For the color codes, see insets).

$(285.9 \mathrm{eV})$ bonds, and that at $\sim 288 \mathrm{eV}$ consisted of $\mathrm{O}=\mathrm{C}-\mathrm{O}$ $(288.1 \mathrm{eV})$ bonds. The spectra from the L-leucine films irradiated with an Ar cluster ion beam at the energy of 10 and $20 \mathrm{keV}$ were almost similar with those from the unirradiated L-leucine film, but the peak corresponding to $\mathrm{O}=\mathrm{C}-\mathrm{O}$ bonds had a slight (less than 10\%) loss in intensity. In contrast, for the L-leucine film irradiated with an Ar monomer ion beam, the peak corresponding to $\mathrm{O}=\mathrm{C}-\mathrm{O}$ had an intensity loss of $\sim 40 \%$. These results suggested that only few $\mathrm{O}=\mathrm{C}-\mathrm{O}$ bonds were broken by irradiation with the Ar cluster ion, but irradiation with the monomer ion beam caused a larger proportion of these bonds to break. The two peaks in Fig. 4(b), the big one at $\sim 401 \mathrm{eV}$ and a smaller one at $\sim 399 \mathrm{eV}$, correspond to $\mathrm{C}-\mathrm{N}$ bonds. L-leucine is stabilized as zwitterion in neutral $\mathrm{pH}$ (Fig. 5). ${ }^{20}$ The electron-escaping energy from the

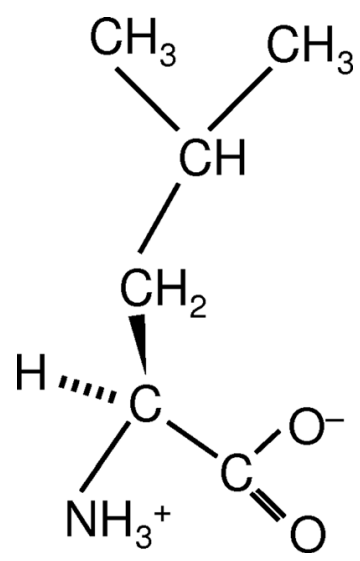

FIG. 5. The structure of L-leucine in zwitterion form.

$\mathrm{N}$ atom affected by the $\mathrm{C}-\mathrm{NH}_{2}$ bond is $399.2 \mathrm{eV}$, and that by the $\mathrm{C}-\mathrm{NH}_{3}{ }^{+}$bond is $401.2 \mathrm{eV}^{21}$ In the unirradiated film, almost all the L-leucine molecules formed as zwitterion, and it did not change with $\mathrm{Ar}$ cluster ion irradiation. In contrast, $\sim 50 \%$ of the $\mathrm{C}-\mathrm{NH}_{3}{ }^{+}$bonds became $\mathrm{C}-\mathrm{NH}_{2}$ with $\mathrm{Ar}$ monomer ion beam irradiation, and the integrated intensity of the $\mathrm{C}-\mathrm{N}$ bonds also decreased by $\sim 10 \%$ after the irradiation with the Ar monomer ion beam. This indicated that the zwitterion structure of L-leucine still remained almost intact after it was irradiated with Ar cluster ion beam irradiation, but could not withstand irradiation with the Ar monomer ion beam. In Fig. 4(c), the peak at the energy of $531.0 \mathrm{eV}$ corresponds to the electron escaped from the $\mathrm{O}$ atom affected by $\mathrm{O}=\mathrm{C}-\mathrm{O}^{-}$bonds. The electron-escaping energy of the $\mathrm{O}$ atom affected by $\mathrm{C}-\mathrm{OH}$ and $\mathrm{O}=\mathrm{C}$ is 532.0 and $533.7 \mathrm{eV}$, respectively, and almost all of the L-leucine molecules formed as zwitterion in the as-received film (Fig. 4(c)). After irradiation with Ar cluster ion beams, the peaks were slightly shifted from $\mathrm{O}=\mathrm{C}-\mathrm{O}^{-}$bonds to $\mathrm{O}=\mathrm{C}-\mathrm{OH}$ bonds. Irradiation with the $\mathrm{Ar}$ monomer ion beam caused a significant decrease in peak intensity of the $\mathrm{O}=\mathrm{C}-\mathrm{O}^{-}$bonds, and peak position has also shifted from $\mathrm{O}=\mathrm{C}-\mathrm{O}^{-}$bonds to $\mathrm{O}=\mathrm{C}-\mathrm{OH}$ bonds. This decrease in intensity is attributed to the selective sputtering effect, as $\mathrm{O}$ atoms were easily sputtered compared with $\mathrm{C}$ or $\mathrm{N}$ atoms. The stoichiometry of the various L-leucine films before and after irradiation with the Ar cluster (10 and $20 \mathrm{keV}$ ) or monomer ion beams is shown in Fig. 6. The $\mathrm{C}$ atom fraction in the unirradiated film was $\sim 70 \%$, and in the film irradiated with the Ar monomer, it increased to $\sim 80 \%$. However, no significant damage was observed on the surface of the films irradiated with the $\mathrm{Ar}$ cluster ion beams. Overall, the XPS results suggested that irradiation of L-leucine films with the Ar monomer ion beam induced heavy damage, which included bond breaking, structural change, and carbonization on the film surface; whereas the Ar cluster ion beam induced little bond breaking or structural change on the surface.

The sputtered film depth increased linearly with irradiation fluence under irradiation with the Ar cluster ion beam (10 and $20 \mathrm{keV}$ ) (Fig. 7). Under irradiation with the $\mathrm{Ar}$ monomer ion, the sputtered depth increased linearly up to a fluence value below $10^{14}$ ions $/ \mathrm{cm}^{2}$, and the slope of the sputtered film depth decreased at a fluence value over $10^{14}$ 


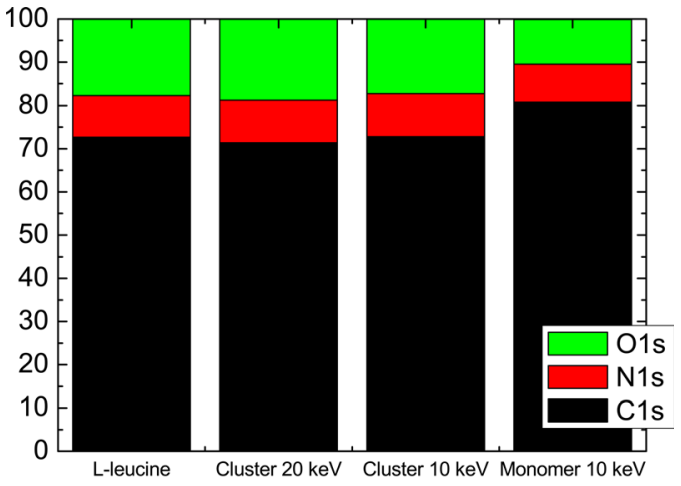

FIG. 6. (Color online) The elemental ratios of L-leucine before and after irradiation with Ar cluster or monomer ion beams.

ions $/ \mathrm{cm}^{2}$. The sputtering yield, which is defined as the number of sputtered molecules per incident ion, can be calculated using the incident ion fluence, sputtered film depth, density, and molecular weight. The sputtering yield of the L-leucine was $410 \pm 5$ and $170 \pm 5$ molecules with irradiation of one incident cluster ion with energy of 20 and $10 \mathrm{keV}$, respectively, which agreed well with previously reported sputtering yields measured with a contact profiler or ellipsometry. ${ }^{22,23}$ These values were constant over the irradiation fluence range of $10^{14}-10^{15}$ ions $/ \mathrm{cm}^{2}$. With irradiation of the Ar monomer ion, the sputtering yield of L-leucine was $240 \pm 10$ molecules in the linear region $\left(10^{13}-10^{14}\right.$ ions $\left./ \mathrm{cm}^{2}\right)$, decreasing to $3 \pm 1$ molecules in the saturated region $\left(10^{14}-10^{15}\right.$ ions/ $\mathrm{cm}^{2}$ ). With Ar monomer ion irradiation, the sputtering yield of L-leucine in the linear region was similar to that with the Ar cluster, and it approached the sputtering yield of graphite irradiated with the Ar monomer ion (calculated to be 1.1 by a semiempirical formula). ${ }^{24}$ The sputtered volume of Lleucine with irradiation of the Ar cluster at the energy of 10 and $20 \mathrm{keV}$ and with the Ar monomer at the energy of $10 \mathrm{keV}$ was 44,110 , and $64 \mathrm{~nm}^{3}$, respectively, and the sputtered film depth was estimated as approximately $3-5 \mathrm{~nm}$. The sputtering mechanism with cluster ion beams has been explained with the multiple collision effect, which refers to thousands of low energy ions colliding on the sample simultaneously and causing the surface material to be sputtered.

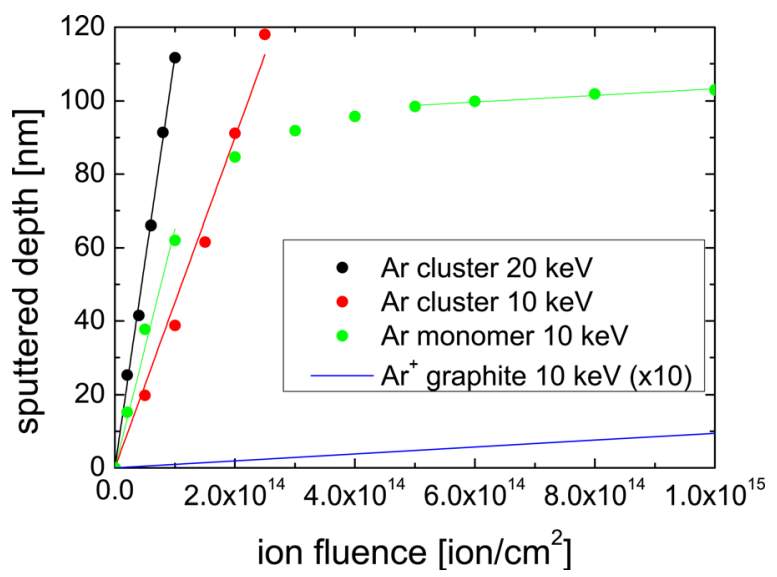

FIG. 7. (Color online) Sputtered depth with Ar cluster or monomer ion irradiation as a function of fluence (for color codes, see inset).
Not every atom in the cluster can penetrate the sample, and the beam projection range would be quite thin $(\sim 1 \mathrm{~nm})$; therefore, the surface damage layer would be removed by sputtering and a damage layer that is quite thin would be localized on the surface. On the other hand, the projection range of the Ar monomer ion beam in L-leucine is $30 \mathrm{~nm}$ and is much deeper than the sputtered film depth. ${ }^{25}$ Thus, the surface damage layer (carbonized layer) cannot be removed by sputtering, and damage would accumulate deep in the sample. This tendency of carbonization by irradiation with the Ar monomer ion beam was consistent with the results of XPS measurements.

\section{CONCLUSIONS}

L-leucine polycrystalline films were characterized before and after irradiation with Ar cluster or monomer ion beams using XPS, which applied to estimate the surface damage on the surface of the L-leucine films, and ellipsometry, which was used mainly to measure sputtering yields. Irradiation with irradiation of an Ar monomer ion beam induced heavy damage, such as bond breaking, structural change, and carbonization on the surface of L-leucine films. The $\mathrm{C}$ atom fraction in the unirradiated film was $\sim 70 \%$ and, in the film irradiated with Ar monomer, it increased to $\sim 80 \%$. However, no significant damage was observed on the surface of the films irradiated with Ar cluster ion beams. Irradiation with Ar monomer ion beams at a fluence of $10^{14}$ ions $/ \mathrm{cm}^{2}$ reduced the L-leucine sputtering yield dramatically, with values approaching the sputtering yield of graphite. This was attributed to accumulation of carbonization damage on the surface of L-leucine films. In contrast, the sputtering yield after irradiation with Ar cluster ion beams was constant with fluence, and all the films were removed with irradiation. These results were consistent with the results obtained by XPS. This study proved that cluster ion beams have the potential to slice down amino acids without significant damage on the surface. As a further application, it is interesting to note that this technique could contribute to various applications in the analysis and fabrication of biological materials.

\section{ACKNOWLEDGMENTS}

This work was partially supported by the Core Research for Evolutional Science and Technology (CREST) program of the Japan Science and Technology Agency (JST). The authors would like to thank S. Hayes in the Max Planck Research Department for Structural Dynamics at the University of Hamburg and R. Manory of http://editassociates.com for help with preparing this material for publication.

${ }^{1}$ E. Pialat, T. Trigaud, V. Bernical, and J. P. Moliton, Mater. Sci. Eng., C 25, 618 (2005).

${ }^{2}$ W. Lin, Y. Lin, W. Wang, B. Yu, S. Iida, M. Tozu, M. Hsu, J. Jou, and J. Shyue, Org. Electron. 10, 459 (2009).

${ }^{3}$ C. H. M. Maree, R. A. Weller, L. C. Feldman, K. Pakbaz, and H. W. H. Lee, J. Appl. Phys. 84, 4013 (1998).

${ }^{4}$ D. Weibel, S. Wong, N. Lockyer, P. Blenkinsopp, R. Hill, and J. C. Vickerman, Anal. Chem. 75, 1754 (2003).

${ }^{5}$ S. Ninomiya, K. Ichiki, H. Yamada, Y. Nakata, T. Seki, T. Aoki, and J. Matsuo, Rapid Commun. Mass Spectrom. 23, 1601 (2009). 
${ }^{6}$ D. E. Williams and L. E. Davis, Characterization of Metal and Polymer Surfaces (Academic, New York, 1977), p. 53.

${ }^{7}$ C. M. Mahoney, A. J. Fahey, and G. Gillen, Anal. Chem. 79, 828 (2007).

${ }^{8}$ J. Matsuo, S. Ninomiya, T. Aoki, and T. Seki, J. Surf. Anal. 14, 196 (2008).

${ }^{9}$ T. Aoki and J. Matsuo, Nucl. Instrum. Methods Phys. Res. B 261, 639 (2007).

${ }^{10}$ T. Seki and J. Matsuo, Nucl. Instrum. Methods Phys. Res. B 261, 647 (2007).

${ }^{11}$ M. Hada, S. Ibuki, S. Ninomiya, T. Seki, T. Aoki, and J. Matsuo, Jpn. J. Appl. Phys. 49, 036503 (2010).

${ }^{12}$ M. Hada, K. Ichiki, and J. Matsuo, Thin Solid Films 519, 1993 (2011).

${ }^{13}$ M. Hada, Y. Hontani, S. Ibuki, K. Ichiki, S. Ninomiya, T. Seki, T. Aoki, and J. Matuso, AIP Conf. Proc. 1321, 314 (2011).

${ }^{14}$ H. C. Koolman and R. W. Rousseau, AIChE J. 42, 147 (1996).

${ }^{15}$ K. Torii and Y. Iitaka, Acta Crystallogr., Sect. B: Struct. Sci. 27, 2237 (1971).

${ }^{16}$ P. Scherrer, Nachr. Ges. Wiss. Goettingen, Math.-Phys. K1. 26, 98 (1918).
${ }^{17}$ A. L. Patterson, Phys. Rev. 56, 978 (1939).

${ }^{18}$ D. E. Aspnes, J. B. Theeten, and F. Hottier, Phys. Rev. B 20, 3292 (1979).

${ }^{19}$ H. Fujiwara, J. Koh, P. I. Rovira, and R. W. Collins, Phys. Rev. B 61, 10832 (2000).

${ }^{20}$ A. Trivella, T. Gaillard, R. H. Stote, and P. Hellwig, J. Chem. Phys. 132, 115105 (2010).

${ }^{21}$ K. B. Yatsimirskii, V. V. Nemoskalenko, V. G. Aleshin, Yu. I. Bratushko, and E. P. Moiseenko, Chem. Phys. Lett. 52, 481 (1977).

${ }^{22}$ M. Hada, S. Ninomiya, T. Seki, T. Aoki, and J. Matsuo, Surf. Interface Anal. 43, 84 (2011).

${ }^{23}$ K. Ichiki, S. Ninomiya, T. Seki, T. Aoki, and J. Matsuo, Appl. Surf. Sci. 255, 1148 (2008).

${ }^{24}$ Y. Yamamura and H. Tawara, At. Data Nucl. Data Tables 62, 149 (1996).

${ }^{25}$ See http://www.srim.org/ for information about the calculated projection range of Ar monomer ion beam in L-leucine. 